\title{
Review
}

\section{Exploring quality of life following high spinal cord injury: a review and critique}

\author{
K Whalley Hammell*,1 \\ ${ }^{1}$ Oxbow, Saskatchewan, Canada
}

\begin{abstract}
Study design: Review.
Objectives: To explore the concept of quality of life (QOL), critique the practice and problems of assessing QOL following spinal cord injury (SCI) and to review the findings of studies into QOL for people with SCI both below and above the level of C4.

Methods: Relevant articles were identified from the Medline and CINAHL databases for approximately the period 1990-2003, cross-indexing 'spinal cord injury' or 'quadriplegia/ tetraplegia' with 'quality of life', 'life satisfaction', 'social adjustment' or 'psychological adaptation'. This search was augmented through papers identified in reference lists. Articles were excluded if they were designed solely to examine the impact of a specific intervention upon QOL; or if they examined satisfaction with various life domains without explicitly linking these to perceptions of QOL. Papers were also accessed that addressed the philosophical and epistemological issues involved in QOL conceptions and assessment.

Results: Review of the literature highlights the philosophical and methodological difficulties associated with the quantitative measurement of a qualitative experience; and with the assessment of life domains chosen by researchers. Analysis of QOL research undertaken among people with all levels of SCI demonstrates that dissatisfaction with life following injury arises primarily from social disadvantage. However, little research has been conducted specifically to ascertain perceptions of QOL among people with high SCI.

Conclusions: Ensuring the relevance of future research into QOL following high SCI requires qualitative methodology and mixed methods. Further research is needed to determine how rehabilitation professionals can act on the findings of their QOL assessments and enhance the QOL experienced by people with spinal cord injury in the context of their environments.

Sponsorship: The early phase of this study was supported by: University of British Columbia Graduate Fellowship; Rick Hansen Man in Motion Foundation (studentship); Social Sciences and Humanities Research Council of Canada: doctoral fellowship.

Spinal Cord (2004) 42, 491-502. doi:10.1038/sj.sc.3101636; Published online 20 July 2004
\end{abstract}

Keywords: spinal cord injury; quality of life; tetraplegia; outcomes; qualitative research

\section{Introduction}

Since the 1980s, people with profound physical impairments caused by spinal cord injury (SCI) at or above the level of $\mathrm{C} 4$ have been surviving in Western countries in increasing numbers. ${ }^{1,2}$ Although a significant body of research has explored perceptions of quality of life (QOL) among people with lower levels of SCI, little research has been undertaken to determine whether people with the highest cord lesions experience quality in living or whether they perceive survival to be worthwhile. ${ }^{2}$ This gap in knowledge and understanding has serious implications. Since biomedical ethics and the law

*Correspondence: KW Hammell, Box 515, Oxbow, Saskatchewan, Canada S0C 2B0 demand a high standard of informed consent for medical interventions, health-care professionals require evidence-based support for the information they provide to patients and their families concerning the possibilities and opportunities for QOL after high SCI. Patterson et $a l^{3}$ asserted that because there are frequent misconceptions about life with a SCI, 'those providing the information must be familiar with the literature' ( $p$ 507). Currently, however, health-care professionals have few resources in the literature upon which to draw., Further, the belief that life with a high SCI would not be worth living pervades Western culture, ${ }^{3,5-7}$ the courts $^{7}$ and the health-care professions, ${ }^{6-13}$ although DeLisa ${ }^{14}$ has noted that the assumptions of those of us 
who are able-bodied bear little relationship to the realities of life for people with spinal cord injury, as shown by multiple investigators' ( $\mathrm{p} 1$ ).

Reflecting prevailing cultural beliefs, health-care professionals have been found to underestimate significantly the QOL experienced by people with high SCI. ${ }^{6-11,15-17}$ Gerhart and Corbet ${ }^{4}$ contend that if the information provided by health-care professionals is coloured by society's negative biases about QOL with an impairment, this may result in 'uninformed consent'. Gerhart $^{6}$ further observed that: 'the implications of acting on, making recommendations because of, or even subtly communicating our quality of life biases are profound. Patients and survivors need accurate information. They need it from their providers, they need it from other survivors, and they need it first hand-gleaned from others' experiences living with a disability. We must educate ourselves, our clients, and the society in which we live' (p 83).

QOL has justifiably become both the ultimate goal of rehabilitation following SCI and a key outcome in determining the effectiveness of rehabilitation programmes for people with SCI. ${ }^{18-21}$ While the need to understand more about the QOL perceived by people with high SCI is undisputed, there are difficulties in studying a concept that lacks a clear definition and which is perceived differently by different people, in differing circumstances and at different times of their lives. This paper explores the concept of QOL, the contentious issues surrounding QOL research and assessment, and outlines the findings of quantitative and qualitative research into perceptions of QOL among people with SCI in general, and high SCI in particular. Finally, it suggests directions for researchers who strive to ensure the relevance and usefulness of their QOL studies; and for rehabilitation clinicians who seek to enhance the quality experienced in the lives of their spinal cord-injured clients.

\section{Assessing QOL following SCI}

The concept of 'quality of life' lacks a clear definition. It has been used within medical research to refer both to the measurable, material conditions of life and to the experiences that make life meaningful and valuable. ${ }^{22}$ Reflecting this inconsistency, no unified approach has been taken towards QOL measurement and no consensus has been achieved on what QOL means, ${ }^{23}$ who should measure it, ${ }^{24}$ or, indeed, whether measurement of quality is a realistic or achievable goal. ${ }^{25,26}$

\section{'Measuring' quality}

The majority of research into QOL following SCI has adopted a quantitative approach, with researchers using single-item rating scales, multiple-item rating scales (addressing general life satisfaction), and multiple-item questionnaires (including items rating satisfaction with specific aspects of life). ${ }^{27} \mathrm{~A}$ thorough exploration of the methodological issues arising from these various approaches has been provided by Dijkers. ${ }^{25}$ Beyond the problems of comparison and cohesion that arise from such inconsistent approaches, quantitative research into QOL is inherently problematic for several reasons.

Primarily, the attempt to quantify a qualitative experience effectively erases the difference between the quantitative and the qualitative. Indeed, the premise that 'quality of life can be quantitatively measured'28 ( $p$ 498) - that the quantity of quality can be computed has been termed an oxymoron. ${ }^{26}$

Further, the categories deemed worthy of consideration in a traditional survey are selected by 'experts', 23,29 whose choices inevitably reflect their own values and culture $^{25,30}$ and can be deemed neither 'neutral' 31 nor 'objective'. ${ }^{25}$ As Mor and Guadagnoli ${ }^{32}$ observed: 'Objectivity' is not bestowed upon a measure merely because another person makes it' (p 1056). Anthropologists and disability researchers note that Western conceptions of QOL reflect culturally specific and not universal values. ${ }^{33}$ Miles $^{34}$ (p 59), for example, observed that while researchers from the dominant Western culture tend to associate QOL with having opportunities for an array of choices, material comforts and the freedom to engage in the 'pursuit of happiness' - and consequently design studies to assess these factors - such discussions appear naive and irrelevant to those whose values are informed, for instance, by Buddhist philosophy, where a life of quality comprises right conduct, right thinking and right living in response to the realities of every-day life.

Wolfensberger $^{35}$ and others ${ }^{29}$ have noted that QOL assessments tend to reflect the norms and values of the dominant culture and privileged classes. Further, Dijkers $^{36}$ observed that many researchers appear to assume that their own judgements about what contributes to QOL are shared by others; that everyone wants the same out of life that they do. Dijkers ${ }^{25}$ observed that QOL measurement is not a value-free endeavour, but one that is inherently political, being informed by assumptions, values and convictions with which the research subject may not agree at all.

In addition, much research has demonstrated the discrepancy between the 'objective' (ie the researcher's) assessment of QOL and the subjective satisfaction with that life. $9,11-13,23,37-42$ Slevin et $a l^{24}$ reported that physicians could not adequately measure a patient's QOL and that there was a wide variability in QOL scores between different physicians and health professionals, even on ostensibly objective scores. This led them to conclude that 'if measurement of a patient's quality of life is required, it should be done by the patients themselves' ( $p$ 110). The researchers observed: 'What constitutes quality of life is a personal and individual question which lends itself to a philosophical rather than a scientific approach' (p 109). DeLisa ${ }^{14}$ cautioned against an over-reliance upon objective indicators - such as measures of functional independence - observing that the relative importance of these indicators to each individual is of far greater importance. However, in their review of quality of life 
measures, Gill and Feinstein ${ }^{23}$ observed that respondents are only rarely provided the opportunity to rate the importance of various factors to their own lives. Indeed, they contend that 'quality-of-life measurements would seem to be aimed at the wrong target unless individual patients are given the opportunity to express their individual opinions and reactions ${ }^{23}$ (p 624). Clayton and Chubon ${ }^{43}$ found that people with SCI who were employed did not perceive their QOL to be significantly better than those who were unemployed, leading them to conclude that this "underscores the limitations in inferring life quality from objective indicators' (p 638).

Some researchers claim to be assessing 'subjective' QOL by using standardized questionnaires that are completed by research 'subjects'. However, reliance upon QOL criteria that have been chosen by researchers constitutes forced 'choices' rather than a truly subjective appraisal of the factors deemed important to individuals' lives based on their own values and priorities. Measures based on those domains selected and ranked by study participants according to their relevance and importance ${ }^{44}$ might more reasonably be termed subjective'. However, Dijkers ${ }^{30}$ observed that in most instances the researchers who develop the QOL instrument (or those who select an existing instrument for use in their own research) define and determine what factors they believe affect QOL. Indeed, how someone attempts to 'measure' QOL perhaps says more about their own values, priorities and fundamental orientation to life than it does about the QOL of the people whose lives are ostensibly being studied.

In seeking to measure QOL after SCI, many researchers have used without comment assessment tools borrowed from geriatric literature. Dunnum, ${ }^{45}$ for example, used the Life Satisfaction for the Elderly Scale with a group of people who were as young as 18 years. The Life Satisfaction Index-A (LSI) ${ }^{46}$ is considered to be most suitable for use with people over 65 years of age ${ }^{47}$ yet has been used in several studies of people with SCI ${ }^{4-50}$ This must be considered in light of evidence that the mean age of SCI in the USA is 32 years and that $55 \%$ of injuries occur among people aged 16-30 years. ${ }^{51}$ Further, while the majority of seniors are women, about $82 \%$ of those with spinal cord injuries are men. ${ }^{51}$ Presumably, these studies are grounded on an assumption that age has no impact upon determinants of QOL and indeed, that a positive score by a young man on a tool designed for elderly women produces a meaningful result. As Dijkers ${ }^{36}$ has noted, the fact that some of the items in the LSI seem appropriate only for elderly people has not prevented researchers from using this tool with young people.

Similarly, Nieves et $a l^{52}$ sought to understand something of the QOL experienced by people with SCI by using the Quality of Life Index, a measure designed for use with patients with cancer. It is surely problematic to apply an assessment designed to reflect the lives of a nondisabled, terminally ill or elderly population to a group that is predominantly young and permanently, profoundly physically impaired. It is possible that researchers have not asked the right questions.

\section{Measuring what counts}

Glass ${ }^{19}$ stated that 'the primary goal [in rehabilitation] must be achieving the highest level of quality of life. Implicit in such a statement is the involvement of the individual in deciding the parameters of quality' (p 123). Gill and Feinstein ${ }^{23}$ concurred that 'quality of life can be suitably measured only by determining the opinions of patients and by supplementing (or replacing) the instruments developed by "experts" (p 619), otherwise "quality of life may continue to be measured with a psychometric statistical elegance that is accompanied by unsatisfactory face validity' ( $p$ 624). More than a methodological issue, the approach taken to QOL 'measurement' is an issue of philosophy and epistemology.

Research has demonstrated the varying degrees of importance that people with SCI place upon specific QOL domains. ${ }^{53}$ Thus, some researchers insist that QOL can only be measured by the individual whose life it is because perceptions necessarily reflect personal values. ${ }^{54}$ Indeed, this epistemological belief led $\mathrm{Dale}^{54}$ to suggest that any claims to have measured the QOL experienced by a patient, using existing standardized 'objective' tools are 'false' and the results of no value.

Many researchers share an underlying assumption: that the determinants of QOL will be the same for both disabled and able-bodied people. ${ }^{55,56}$ This would seem to validate assessment criteria established for disabled people by able-bodied researchers; but how can we know this? The vast majority of research that compares the views of people with and without impairments has relied upon criteria predetermined by the researcher's view of life; an instance of forced 'choices' ${ }^{31,57}$ Dijkers ${ }^{5}$ noted that disabled people are frequently shown to have a lower QOL than non-disabled people if 'objective' measures are considered but that they do not have a lower subjective QOL.

Farquhar $^{58}$ reported that after enduring prolonged institutionalization, people might wish to include determinants of QOL that include concepts of privacy, freedom, choice and dignity: concepts rarely considered by those researchers who have always been able to take such rights for granted.

Fundamentally, the difficulty of assessing QOL centres on the problem of understanding a life different from one's own and of its value to the person whose life it is. ${ }^{59}$ Walsh $^{59}$ suggested that people who have high lesion tetraplegia will do badly on any scale that employs objective factors to measure QOL, proposing that: 'the subjective experience of a life is more important than its outward expression, ${ }^{59}$ (p 144). To understand this subjective experience demands research methods that can probe both the content and the context of that life. 


\section{Reconciling conflicting viewpoints}

Researchers have demonstrated discrepancies between objective assessment of QOL and the subjective assessments of the quality of those same lives, ${ }^{9,11-13,23,37-41,60}$ as has been noted. These discrepancies have led some researchers to claim that patients' subjective assessments require objective (or outside) corroboration by adding a quantitative measure to qualitative research. ${ }^{31,61-64}$ Perhaps because the quantitative paradigm predominates among medical researchers, ${ }^{65}$ it is less commonly argued that quantitative findings require qualitative corroboration. ${ }^{66}$ The contention that subjective findings require objective corroboration does not enjoy universal support. Creswell ${ }^{67}$ noted that 'Qualitative inquiry represents a legitimate mode of social and human science exploration without apology or comparisons to quantitative research' (p 9).

Within the health-care professions, knowledge claimed to be objective or scientific ('ours') has traditionally been accorded privilege over expertise derived from lived experience ('theirs'), ${ }^{68}$ because while health-care professionals consider themselves to have 'knowledge', patients are deemed to have 'beliefs': 'Knowledge requires both certitude and correctness; belief implies uncertainty, error, or both'69 (p 17). Accordingly, Bach ${ }^{61}$ has argued that subjective assessments ought not to be relied upon, because they sometimes deny what are 'known to be basic conditions of quality of life' ( $p$ 130), although he did not state what these conditions are, or to whose certain knowledge he refers. Bach claimed that at an intuitive level, researchers 'know' that some conceptions of QOL are better than others and to deny this is to fall into an unacceptable ethical relativism. Holmes $^{62}$ concurred: 'it makes little sense to assert that people who, in appalling circumstances, nevertheless regard themselves as enjoying a high quality of life, do indeed have a high quality of life' (p 836). It has been suggested that those people who report high life satisfaction in poor circumstances do so as a result of 'false consciousness' and limited expectations. ${ }^{31}$ There are three fundamental problems with this position.

First, people with high lesion tetraplegia, who are completely paralysed below the neck and who require assistance for every daily life task could, without question, be viewed as living in 'appalling circumstances'. Indeed, these circumstances lead many people to conclude that death would be preferable to life in this condition $^{5,6}$ and prompted Menter ${ }^{70}$ to observe that 'high-level spinal cord injury with complete paralysis below the fourth cervical neurologic level is one of the most devastating catastrophes that can befall an individual' ( $\mathrm{p} v$ ). People with high SCI would be seen, by some, as enjoying few of what are 'known' to be basic conditions of QOL, ${ }^{61}$ but they are also unusual among severely disabled people, in that they have experienced another form of living and thus have some expectations for comparison. Yet, researchers have found that, "while surely living at the edge of what is tolerable for human beings they express a strong desire to continue living, ${ }^{59}$ (p 144).

Further, if researchers reject the positive perceptions of QOL reported by people who it is believed lack the basic conditions for a life of quality, they must also reject the negative assessments of QOL among people whose privileged circumstances demonstrate that they do, by objective appraisal, enjoy a high degree of QOL. This position is difficult to maintain, given the dissatisfaction with life reported by many people who possess both health and wealth. ${ }^{71}$ Indeed, the reality that depression is considered to be an epidemic in the minority ('developed') world despite comparative affluence, material comforts and what is termed a high 'standard of living,' 71 suggests that the experience of quality in living is not dependent upon the quantifiable, material conditions of life but upon subjective qualitative factors: the content and context of life.

Finally, social scientists recommend caution in applying a term such as 'false consciousness' to other people. This concept, originated by Marxists, $^{72}$ is deemed to constitute any idea or ideology that is held to be inappropriate in light of the 'real' or 'objective' situation as this is more 'correctly' perceived by those wielding greater power. Social scientists contend that use of the term 'false consciousness' implies that the truth of a given situation is understood correctly and with certitude by someone possessing a superior consciousness and suggest that use of the term demonstrates contempt for those whose perceptions are being disparaged. ${ }^{72-74}$

\section{QOL following SCI: quantitative findings}

A small number of researchers have reported that perceptions of satisfactory QOL are negatively correlated with the level of spinal cord lesion, ${ }^{10,43,75,76}$ although this association is not generally found to be statistically significant. ${ }^{36}$ In contrast, a substantial body of research has found no correlation between QOL/life satisfaction and level of SCI: the degree of impairment or extent of physical independence. $9,15,20,48,49,52,60,77-106$

Meta-analyses of research into QOL following SCI reported by Evans et $a l^{75}$ and Dijkers ${ }^{36}$ have demonstrated the wide variety of research designs and instruments, modes of analysis and sample characteristics that make comparisons and overall conclusions problematic. These difficulties were further explored in a review published by Hallin et al, ${ }^{107}$ who identified the need for 'carefully constructed condition-specific instruments that can capture dimensions of specific interest for the SCI population' ( $p$ 520). Researchers have noted that the number of different instruments used to evaluate QOL following SCI nearly equals the number of studies conducted. ${ }^{55,107}$ Attempts to compare findings from multiple studies are impaired due to conceptual ambiguity surrounding the use of different terms, such as 'life satisfaction', 'well-being' and 'quality of life'. Indeed, Ville et $a l^{108}$ note that these terms are sometimes used interchangeably without being clearly defined. 
Quantitative research among people with all levels of SCI has demonstrated positive correlations between QOL/ life satisfaction and: self-assessed health ${ }^{48,49,87,102,106,109-111}$ perceived social support, ${ }^{48-50,86,100,102,109,110}$ social func-

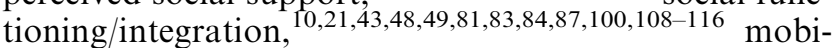
lity, ${ }^{10,49,83,87,88,106,111}$ accessibility (home/health care ${ }^{117}$ ), preferred living situation, ${ }^{77}$ adequate income, ${ }^{43,85,108,117}$ perceptions of having control over one's life, ${ }^{48,49,88,109,110,118-120}$ marital status, ${ }^{10,76,106,108,121}$ satisfaction with relationships ${ }^{88,122}$ community access/ participation $^{36,43,49,95,110,112,123}$ and satisfaction with occupational engagement and/or employment status. ${ }^{10,48,49,76,82,83,87,88,100,102,108,113,115,121,124-126}$ There have been conflicting reports of the relationships between age, length of time since injury, gender and 'race' with perceptions of QOL. However, because none of these factors is susceptible to intervention, these findings have been deliberately omitted. Other studies were omitted if they assessed satisfaction with specific researcher-identified domains (eg employment status, living arrangements or CHART domains) without explicitly ascertaining whether these domains contributed to the study participants' perceptions of QOL.

Life satisfaction/QOL has been reported to be negatively correlated with: rehospitalizations/ perceptions of poor health (including respiratory problems and pressure sores), ${ }^{7,81,87,106}$ pain, ${ }^{81,82,84,85,108,115,122,127-129}$ spasticity, ${ }^{81}$ inadequate income ${ }^{79,118}$ reduced life opportunities, ${ }^{118,127}$ reduced social interaction, ${ }^{87,127}$ loneliness and boredom, ${ }^{124}$ unemployment/dissatisfaction with occupations, ${ }^{87,126}$ reduced mobility, ${ }^{87}$ residence in a nursing home, ${ }^{10,60}$ and perceptions of having reduced control over one's life. ${ }^{87,124,127}$

Researchers who use standardized questionnaires to assess various dimensions of QOL will find only what they are looking for because specific questions inevitably restrict the range of possible responses. Pain, for example, might more generally be experienced as detracting from the experience of quality in living, but if it is not included in researchers' measures, it will not be included in their findings. Further, existing measures may not include those factors that people with SCI feel are important contributors to the quality of their lives. $^{29}$

\section{QOL following SCI: qualitative findings}

Few qualitative studies have been undertaken to explore QOL following SCI from survivors' perspectives, despite increasing recognition of the value of this approach for exploring both the meaning of QOL for people with SCI and the factors they identify as contributing to the quality of their lives. ${ }^{10,15,18,25,29,41,78,83,130-136}$

Bach and $\mathrm{McDanie}^{137}$ held focus groups with 14 people whose level of SCI ranged from $\mathrm{C} 4$ to C8. Length of time since injury was up to 15 years. Thematic analysis of their data identified six determinants of QOL that would be similar to those of the general population $^{138}$ (and thus likely to be included in traditional
QOL research): relationships, work and productivity, finances, health, having inner resources and control of one's life, and level of activity. However, two additional components were identified: assertiveness, and balancing dependence and independence.

Another study in the USA sought to explore the life domains that 12 people with SCI felt contributed to QOL. ${ }^{53,139}$ Study participants defined QOL as a subjective experience that changed throughout life in response to changing priorities. They identified the following domains as strong influences on perceptions of QOL: attitude towards life, and opportunities to contribute and create through occupation. The availability of resources was described as being a necessary foundation for QOL (including attendant care, transportation and adequate income). These domains were described as being 'interdependent' and 'interactive', in that each domain that was considered to be an important contributor to QOL was dependent upon other important domains. Participation in meaningful occupations, for example, was dependent upon having reliable, quality attendant care. The researchers, therefore, proposed that the interaction of life domains should be considered important in assessing QOL. ${ }^{53}$

Duggan and Dijkers ${ }^{140,141}$ undertook a qualitative study to describe subjective QOL among 40 people with SCI. While few participants could define QOL, the majority could identify indicators of QOL and they were able to provide clear ratings of their own QOL. QOL ratings were highest among those who had satisfying relationships, meaningful social roles, financial security and material assets, and the opportunity to pursue valued occupations (such as hobbies, travel or community service). Issues related to personal development and changes in values were also of significance. The data suggested that a complex relationship between personality attributes (outlook and values), material conditions and the passage of time since injury lead to higher perceived QOL. ${ }^{141}$ Echoing the findings of Boswell et $a l^{53,139}$ the researchers identified a complex relationship between various QOL domains, suggesting that each domain, on its own, is insufficient to imbue life with quality. Rather, it is the interaction of relationships and meaningful roles, or material assets and occupations (for example) that contributes to the experience of quality in living for people with SCI. QOL might best be understood, therefore, to be a multidimensional matrix, rather than a set of unidimensional cause-andeffect relationships.

As part of their larger project, ${ }^{140,141}$ Duggan and Dijkers ${ }^{142}$ reported a smaller, comparative study that explored the differences in outcomes between 10 people who sustained SCI as a result of interpersonal violence and 10 people whose SCIs were the result of other aetiologies. Both groups cited the importance of social relationships and social support to the experience of QOL. The factors that were identified as contributing to QOL for those with non-violence-related injuries were at the opposite end of a continuum of factors identified as detracting from QOL by those whose injuries resulted 
from violence: financial independence/financial pressures; having an accessible home/not having an accessible home; having meaningful work roles/not having meaningful work roles. In addition, those with SCIs related to violence cited other community barriers as negative factors. This report demonstrates how smallscale, qualitative studies can be used to identify and probe contextual issues that might be missed by using a standardized questionnaire and a large study population.

Noting that there has recently been a significant increase in the percentages of people with SCI who are being discharged to nursing homes in the USA, Duggan et $a l^{143}$ undertook a longitudinal, qualitative study into the impact of nursing home residence on the QOL experienced by six people with SCI. Two findings are particularly notable. People were sent to nursing homes on the basis, not of the severity of their impairments, but of their lack of social and economic power. Powerlessness and denial of the opportunity to exert any control over their own bodies or lives also characterized their nursing home experiences. In addition, the factors that were identified as inserting some quality into their lives - for example, having their teeth brushed at least twice a week, or their hair washed at least twice a month - demonstrated the irrelevance of most standard QOL measures. The researchers note: 'Researchers of QOL would hardly think of investigating whether privacy, control over one's body, and the ability to leave one's home affect life satisfaction ratings because they are so basic and not lacking in the lives of most people' ( $p$ 127). Their findings provide evidence-based support for the premise that QOL can only be measured by the individual whose life it is, according to their own values and experiences; and that existing measures may not be asking the relevant questions.

Duggan and Lysack ${ }^{144}$ provide a brief report of a qualitative investigation into changes in self-rated QOL from the onset of SCI to 30 months postinjury. Although they found that QOL declined sharply 6 months after injury, for many, although not all the respondents self-related QOL improved at 1 year after injury. The researchers attributed this upward trajectory to the passage of time, a change in values and a revised self-concept. The researchers suggest that QOL would appear to be a complex equation of impairment factors, personal factors and environmental factors.

Although some previous investigators have highlighted the importance of value change $e^{10,25,53,142,145,146}$ and of revised self-concept ${ }^{142,147}$ to perceptions of QOL, these factors have not been pursued by QOL researchers, perhaps because they are not readily amenable to quantitative analysis. However, suggestion that the parameters of QOL are unstable - that the goal-posts keep moving - requires consideration in any attempt to assess or measure QOL.

\section{QOL following high SCI: quantitative findings}

In the absence of studies to the contrary, it cannot be assumed that the determinants of life satisfaction will be the same for people who are paralysed from the neck down as they are for people who have lower levels of SCI, some residual use of their arms and hands and higher degrees of physical independence. However, it does not appear that qualitative studies have been undertaken to explore QOL from the perspectives of people with high SCI, and the following brief review is undertaken solely with quantitative studies.

One of the earliest papers to examine adjustment to life with a high SCI (above C4) identified the need for rehabilitation professionals to assist the individual in achieving control of his or her life and environment and to provide consistent support and a source of reference during the search for a meaningful life. ${ }^{148}$

The first comprehensive study of people with highlevel tetraplegia studied 216 people with lesions at $\mathrm{C} 4$ or above. In all, $92 \%$ of the study participants reported to be glad to be alive at the time of the study. Each person was asked to rate his or her overall QOL on a 5-point scale, from excellent to very poor. Fully $86 \%$ of the group reported that they enjoyed an average or better than average QOL. Level of activity was significantly correlated $(P<0.001)$ with both QOL and self-esteem. ${ }^{149}$

In the UK, eight community-dwelling people with ventilator-dependent high SCI were asked about their satisfaction with their current lives. Every person stated they were glad to be alive and they were unanimous that the most important factor contributing to QOL was the quality of their relationships with families and friends. All the respondents identified the importance to their lives of maintaining high levels of activity. ${ }^{80}$

Fuhrer et $a l^{150}$ examined the educational and employment situation of people with high lesion tetraplegia approximately 1 year following discharge. They did not explore any other indicators of QOL but noted that because readaptation to home and community life following such profound injury takes a considerable period of time, appreciation of the life situation of people who are tetraplegic and ventilator dependent requires studies that track such individuals for a lengthy period of time.

Bach and Tilton ${ }^{9}$ sought to evaluate the effect of complete traumatic tetraplegia on the life satisfaction and well-being of 87 people. The authors did not provide the lesion levels of their respondents, although all had complete cervical injuries and were at least 2 years since discharge. No significant differences were found in any of the life satisfaction domains between the 45 respiratory independent and 42 ventilator-supported individuals. On a scale of 1-7 (with 1 being completely dissatisfied), the mean life satisfaction of the respiratory independent group was 4.11 and was 4.39 among the ventilator assisted group. ${ }^{16}$

Bach and Barnett ${ }^{17}$ used a questionnaire to assess life satisfaction among 27 people with ventilatordependent tetraplegia. At a mean of 13 years since injury, $69 \%$ of the SCI ventilator users claimed to be satisfied with their lives, demonstrating a strong belief that life was 'worthwhile'. 
Hall et $a l^{2}$ undertook a follow-up study to that reported by Whiteneck et $a l^{149}$ a decade earlier. Their study population comprised 91 people with complete cord lesions at $\mathrm{C} 4$ and above. In response to the question: 'are you glad to be alive?', 88 out of 91 people responded 'yes'. All individuals were asked to rate their overall QOL on a five-point scale. Among the ventilator-assisted group, $83 \%$ rated their QOL as either excellent or good, as did $72 \%$ of the respirator independent group. Compared to the 1985 study findings, ${ }^{149}$ the follow-up study in 1994 found that the participants were much more active and demonstrated higher self-esteem ratings. The researchers concluded that the high levels of activity and community integration exhibited by their participants, the satisfaction they reported with the quality of their lives and their longevity clearly demonstrated that people with high lesion tetraplegia have the potential for excellent QOL.

Although media and case reports indicate that suicide may sometimes be preferred to life with a high SCI, ${ }^{151,152}$ the research literature suggests that people with high SCI can attain meaningful lives and the experience of quality in living. However, because there are no reports of qualitative studies that have sought to explore QOL following high SCI from the perspectives of survivors, little is yet known about the dimensions that contribute to - and detract from - the experience of QOL after high SCI.

\section{Future directions: research}

DeLisa ${ }^{14}$ suggested that reducing the gap between traditional outcome measures and the needs of people with SCI requires researchers to ensure that their research is guided by those outcomes that are valued most highly by SCI survivors. Many variables contribute to the formation of values, including education, professional and employment status, material wealth, gender, 'race', ethnicity, age, social class/caste, sexual orientation, marital status, [dis]ability and religion and there may be a poor match between the values and priorities of researchers and their 'subjects'. In addition, several researchers have suggested that a serious injury can prompt a revision of values and a re-evaluation of the dimensions that are considered to be personally important and to be contributors to QOL. ${ }^{10,25,53,142,145,146}$ These discrepant values pose a challenge to researchers.

Boswell ${ }^{139}$ found that a group of people with SCI identified different 'QOL domains' through a process of ranking predetermined categories than were identified in focus group discussions. The domains included in the questionnaire were ones commonly used in QOL studies (eg by Kinney and Coyle ${ }^{153}$ ) and indicated the following items as most salient: family relationships, physical and psychological well-being. Coding of the focus groups' transcripts indicated that the three most important domains were attitude toward life, work opportunities and resources. Boswell attributed this discrepancy in findings to the lack of participant input permitted in ranking the questionnaire, highlighting the inherent problems in seeking to assess the QOL using predetermined categories. Mixing qualitative and quantitative research methods may be a promising direction for future research into QOL after SCI.

\section{Mixing quantitative and qualitative methods}

Researchers recognize that in many instances the nature of a research issue and its contextual nature require the use of both qualitative and quantitative methods to tease out and illuminate different dimensions of this complexity. ${ }^{65,154-156}$ Since perceptions of QOL are necessarily context-specific and imbued with subjective meanings, mixing methods would seem to be especially appropriate in QOL research.

Quantitative and qualitative methods may be mixed using sequential or concurrent designs. In the sequential design, one method informs the other. Typically, qualitative research precedes quantitative research by exploring both the context and the meanings of an issue - such as QOL - to the study participants. This enables the identification of variables that might be measured and statistically analysed, ensuring that the language used will be clear to study respondents. ${ }^{154,156-159}$ Conversely, Mallinson ${ }^{160}$ employed qualitative methods to evaluate patients' experiences with an existing quantitative research tool: the Short-Form 36 Health Status Questionnaire. Mallinson's findings prompted her to observe: 'without more assessment of people's understandings of survey questions it is difficult to see how one can establish their validity as subjective health measures' (p 20).

Concurrent designs may be used to explore both what happens (using quantitative methods) and why, and in which specific contexts (using qualitative methods). ${ }^{156}$ Using concurrent qualitative and quantitative methods in QOL research may potentially produce findings which appear contradictory, ${ }^{139}$ thus requiring sensitive analysis and careful examination of discrepancies and inconsistencies. ${ }^{161}$ As Hansen et al ${ }^{123}$ have proposed, 'We must challenge ourselves to consider other variables...that have received little attention, to listen to our subjects, and to consider a variety of methodologies' (p 71).

Qualitative evidence is increasingly being used as a basis for evidence-based practice ${ }^{162}$ and the British National Health Service Centre for Reviews and Dissemination has recognised the importance of qualitative evidence in systematic reviews. ${ }^{63}$ The systematic review is a rigorous and explicit research method that aims to locate, appraise and synthesize the findings of multiple studies pertaining to a specific research question. ${ }^{164,165}$ Some researchers perform systematic reviews that employ a quantitative meta-analysis in concert with a qualitative meta-synthesis. ${ }^{166}$ It is possible that metasyntheses of qualitative research exploring the perceptions of people with SCI concerning their own QOL how they assess this, what factors are perceived to contribute to, or detract from the experience of a life 
worth living - might provide a client-centred and evidence-based foundation for future assessments of QOL following SCI.

\section{Future directions: rehabilitation}

The Consortium for Spinal Cord Medicine ${ }^{15}$ stated that 'analysis of the factors that are likely to influence quality of life may help to focus interventions that could maximize quality of life outcomes' (p 24). Because analysis of the factors that have been found to influence QOL outcomes demonstrates that dissatisfaction with life after SCI predominantly arises, not from the injury, per se, but from social disadvantage, the process of focusing interventions towards maximizing QOL outcomes will require a bold stand.

Safilios-Rothschild ${ }^{167}$ found that 'rehabilitation entails a highly stressful resocialization process into an 'inferior' status' and that the process of 'accepting' disability necessitates 'the relinquishing of majority status rights' ( $\mathrm{p}$ 7). 'Adjustment' to disability, it is argued, is not so much a psychological process but a process of adjusting to changes in others' perceptions, in social positioning, and in access to educational, economic and social opportunities. ${ }^{168}$ Indeed, the onset of impairment has been described as the experience of a 'fall from privilege" ${ }^{\text {"69 }}$ (p 184).

The rehabilitation professions claim to be involved in striving to enhance the quality of their clients' lives. ${ }^{18,19}$ It is, perhaps, ironic, that the professionals who enjoy the greatest prestige, renumeration and research funding are those engaged in seeking to reduce the impact of impairments. The therapy professions, which enjoy more limited privileges, focus, primarily, upon enhancing physical independence, yet neither degree of impairment nor level of independence correlate with perceptions of QOL. Advocacy for changes in those social policies and conditions that appear to have the strongest impact upon perceptions of QOL among people with SCI are left, almost exclusively, to unpaid disability activists and their supporters. Indeed, it has been claimed that rehabilitation professionals have an unauspicious record in the struggle to change social policies that might benefit disabled people, tending to reserve advocacy in the political and institutional arenas for issues pertaining to their own professional interests. ${ }^{170}$

Chase et $a l^{171}$ observed that understanding the components that are important to QOL for people with SCI is 'the first step in making it a reality' ( $p$ 18). However, this is only the first step. There would be little point in measuring range of motion (ROM) unless the rehabilitation professions were committed to enhancing reduced ROM. Similarly, there would seem little merit in documenting either the considerable social disadvantage that accompanies SCI (eg using CHART) or measuring the diminished QOL experienced by those who are sent to nursing homes, or who experience occupational deprivation and other forms of social disadvantage, unless the rehabilitation professions are committed to working to alleviate these conditions also.

If the medical and rehabilitation professions are to take seriously the results of our research, a way must be found to address the problems associated with SCI at both the cellular and the societal levels. If it is acknowledged that social, physical, economic, legal and political environments increase the problems confronted by people with SCI and reduce the quality of their lives then interventions must be targeted not solely at individuals - teaching them to live in a world designed to meet the needs of the dominant population - but at influencing public policies and community planning. ${ }^{172,173}$ Commitment to reducing, for example, pain, spasticity, pressure sores and respiratory problems (factors equated with poor QOL) should be matched by a commitment to reducing, for example, nursing home admissions, occupational deprivation, inadequate access to health-care and poverty (also factors associated with poor QOL). How this might be accomplished would be a worthy avenue for future research.

\section{References}

1 DeVivo MJ, Ivie CS. Life expectancy of ventilatordependent persons with spinal cord injuries. Chest 1995; 108: $226-232$.

2 Hall KM, Harper B, Whiteneck GG. Follow-up study of individuals with high tetraplegia (C1-C4) 10 to 21 years post-injury. Top Spinal Cord Injury Rehabil 1997; 2: 107-117.

3 Patterson DR, Miller-Perrin C, McCormick TR, Hudson LD. When life support is questioned early in the care of patients with cervical-level quadriplegia. $N$ Eng $J$ Med 1993; 328: 506-509.

4 Gerhart KA, Corbet B. Uninformed consent: biased decision-making following spinal cord injury. HEC Forum 1995; 7: 110-121.

5 Dijkers M. Quality of life after spinal cord injury. Am Rehabil 1996; Autumn: 18-24.

6 Gerhart KA. Quality of life: the danger of differing perceptions. Top Spinal Cord Injury Rehabil 1997; 2: 78-84.

7 Zandrow LF. Misguided mercy: hastening death in the disability community. Top Spinal Cord Injury Rehabil 2001; 6: $76-82$.

8 Gardner BP, Theocleous R, Watt JW, Krishnan K. Ventilation or dignified death for patients with high tetraplegia. $B M J$ 1985; 292: 160-162.

9 Bach JR, Tilton MC. Life satisfaction and well-being measures in ventilator assisted individuals with traumatic tetraplegia. Arch Phys Rehabil 1994; 75: 626-632.

10 Dijkers M. Correlates of life satisfaction among persons with spinal cord injury. Arch Phys Med Rehabil 1999; 80: 867-876.

11 Gerhart KA, Koziol-McLain J, Lowenstein SR, Whiteneck GG. Quality of life following spinal cord injury: knowledge and attitudes of emergency care providers. Ann Emerg Med 1994; 23: 801-812.

12 Bach JR. Ventilator use by muscular dystrophy association patients. Arch Phys Med Rehabil 1992; 73: 179-183.

13 Bach JR, Campagnolo DI. Psychosocial adjustment of post-poliomyelitis ventilator-assisted individuals. Arch Phys Med Rehabil 1992; 73: 934-939. 
14 DeLisa JA. Quality of life for individuals with SCI: let's keep up the good work. Spinal Cord Med 2002; 25: 1.

15 The Consortium for Spinal Cord Medicine. Outcomes following traumatic spinal cord injury: Clinical practice guidelines for health care professionals. The Consortium and the Paralyzed Veterans of America, Washington 1999.

16 Tilton MC, Bach JR, Wang T-G. Life satisfaction measures: comparison of ventilator supported spinal cord injured individuals with those free of ventilatory support. J Am Paraplegia Soc 1993; 16: 253.

17 Bach JR, Barnett V. Psychosocial, vocational, quality of life, and ethical issues. In: Bach JR, (ed). Pulmonary Rehabilitation: The Obstructive and Paralytic Conditions. Hanley and Belfus Inc.: Philadelphia 1996, pp 395-411.

18 Whiteneck GG. Outcome evaluation and spinal cord injury. Neurorehabilitation 1992; 2: 31-41.

19 Glass CA. Spinal Cord Injury: Impact and Coping. British Psychological Society: Leicester 1999.

20 Manns PJ, Chad KE. Determining the relation between quality of life, handicap, fitness, and physical activity for persons with spinal cord injury. Arch Phys Med Rehabil 1999; 80: 1566-1571.

21 May LA, Warren S. Measuring quality of life of persons with spinal cord injury: external and structural validity. Spinal Cord 2002; 40: 341-350.

22 Roy DJ. Editorial. Measurement in the service of compassion. J Palliat Care 1992; 8: 3-4.

23 Gill TM, Feinstein AR. A critical appraisal of the quality of Quality-of-life measurements. JAMA 1994; 272: 619-626.

24 Slevin ML, Plant H, Lynch D, Drinkwater J, Gregory WM. Who should measure quality of life, the doctor or the patient? Br J Cancer 1988; 57: 109-112.

25 Dijkers M. Measuring quality of life: methodological issues. Am J Phys Med Rehabil 1999; 78: 286-300.

26 Hammell KW. Representation and accountability in qualitative research. In: Hammell $\mathrm{KW}$, Carpenter $\mathrm{C}$, Dyck I. (eds). Using Qualitative Research. A Practical Introduction for Occupational and Physical Therapists. Churchill Livingstone: Edinburgh 2000, pp 59-71.

27 Post MWM, VanDijk AJ, Van Asbeck FWA, Schrijvers AJP. Life satisfaction of persons with spinal cord injury compared to a population group. Scand J Rehabil Med 1998; 30: 23-30.

28 Kennedy P, Rogers B. Reported quality of life of people with spinal cord injuries: a longitudinal analysis of the first 6 months post-discharge. Spinal Cord 2000; 38: 498-503.

29 Johnston M, Nissim E, Wood K, Hwang K, Tulsky D. Objective and subjective handicap following spinal cord injury: interrelationships and predictors. J Spinal Cord Med 2002; 25: 11-22.

30 Saravanan B, Manigandan C, Macaden A, Tharion G, Bhattacharji S. Re-examining the psychology of spinal cord injury: a meaning centred approach from a clinical perspective. Spinal Cord 2001; 39: 323-326.

31 Najman JM, Levine S. Evaluating the impact of medical care and technologies on the quality of life: a review and critique. Soc Sci Med 1981; 15: 107-115.

32 Mor V, Guadagnoli E. Quality of life measurement: a psychometric Tower of Babel. J Clin Epidemiol 1988; 41: 1055-1058.

33 Whyte SR, Ingstad B. Disability and culture: an overview. In: Ingstad B, Whyte SR (eds). Disability and Culture. University of California Press: Berkeley, CA 1995, pp 3-32.

34 Miles M. Disability in an Eastern religious context: historical perspectives. Disabil Soc 1995; 10: 49-69.
35 Wolfensberger W. Let's hang up 'quality of life' as a hopeless term. In: Godde D (ed). Quality of Life for Persons with Disabilities: International Perspectives and Issues. Brookline Books: Cambridge, MA 1994, pp 285-321.

36 Dijkers M. Measuring quality of life. In: Fuhrer MJ (ed). Assessing Medical Rehabilitation Practices. The Promise of Outcomes Research. Paul Brookes: Baltimore, MD 1997, pp 153-179.

37 Bodenhamer E, Achterberg-Lawlis J, Kevorkian G, Belanus A, Cofer J. Staff and patient perceptions of the psychosocial concerns of spinal cord injured persons. Am J Phys Med 1983; 62: 182-193.

38 Ernst FA. Contrasting perceptions of distress by research personnel and their spinal cord injured subjects. Am J Phys Med 1987; 66: 12-15.

39 Cushman L, Dijkers M. Depressed mood in spinal cord injured patients: staff perceptions and patient realities. Arch Phys Med Rehabil 1990; 71: 191-196.

40 Bach JR, Campagnolo DI, Hoeman S. Life satisfaction of individuals with Duchenne muscular dystrophy using long-term mechanical ventilatory support. Am J Phys Med Rehabil 1991; 70: 129-135.

41 Loew L, Rapin H. The paradoxes of Quality of Life and its phenomenologic approach. J Palliat Care 1994; 10: $37-41$.

42 Woodend AK, Nair RC, Tang AS. Definition of life quality from a patient versus health care professional perspective. Int J Rehabil Res 1997; 20: 71-80.

43 Clayton KS, Chubon RA. Factors associated with the quality of life of long-term spinal cord injured persons. Arch Phys Med Rehabil 1994; 75: 633-638.

44 O'Boyle CA, McGee H, Hickey A, O’Malley K, Joyce CRB. Individual quality of life in patients undergoing hip replacement. Lancet 1992; 339: 1088-1091.

45 Dunnum L. Life satisfaction and spinal cord injury: the patient perspective. J Neurosci Nurs 1990; 22: 43-47.

46 Neugarten BL, Havighurst RJ, Tobin SS. The measurement of life satisfaction. J Gerontol 1961; 16: 134-143.

47 Adams DL. Analysis of a Life Satisfaction Index. J Gerontol 1969; 24: 470-474.

48 Crisp R. The long term adjustment of 60 persons with spinal cord injury. Austr Psychol 1992; 27: 43-47.

49 Fuhrer MJ, Rintala DH, Hart KA, Clearman R, Young ME. Relationship of life satisfaction to impairment, disability and handicap among persons with spinal cord injury living in the community. Arch Phys Med Rehabil 1992; 73: 552-557.

50 Rintala DH, Young ME, Hart KA, Clearman RR, Fuhrer MJ. Social support and the well-being of persons with spinal cord injury living in the community. Rehabil Psychol 1992; 37: 155-163.

51 National Spinal Cord Injury Statistical Centre. Spinal cord injury Facts and figures at a glance. $J$ Spinal Cord Med 2002; 25: 52.

52 Nieves CC, Charter RA, Aspinall MJ. Relationship between effective coping and perceived quality of life in spinal cord injured patients. Rehabil Nurs 1991; 16: 129-132.

53 Boswell BB, Dawson M, Heininger E. Quality of life as defined by adults with spinal cord injuries. J Rehabil 1998; 64: $27-32$.

54 Dale AE. A research study exploring the patient's view of quality of life using the case study method. $J$ Adv Nurs 1995; 22: 1128-1134. 
55 Jamieson J, Schmidt T, Britton B. Adults with a Mental Handicap: Their Quality of Life. Province of British Columbia: Ministry of Social Services, Victoria 1993.

56 Brown I, Renwick R, Nagler M. The centrality of quality of life in health promotion and research. In: Renwick R, Brown I, Nagler M (eds). Quality of Life in Health Promotion and Rehabilitation. Sage: Thousand Oaks, CA 1996, pp 3-13.

57 Day H, Jankey SG. Lessons from the literature. Toward a holistic model of quality of life. In: Renwick R, Brown I, Nagler M (eds). Quality of Life in Health Promotion and Rehabilitation. Sage: Thousand Oaks, CA 1996, pp 39-50.

58 Farquhar M. Quality of life in older people. Adv Med Sociol 1994; 5: 139-158.

59 Walsh P. Tetraplegics and the justice of resource allocation. Paraplegia 1993; 31: 143-146.

60 Putzke JD, Richards JS. Nursing home residence Quality of life among individuals with spinal cord injury. $\mathrm{Am} \mathrm{J}$ Phys Med Rehabil 2001; 80: 404-409.

61 Bach M. Quality of life: questioning the vantage points for research. In: Rioux MH, Bach M (eds). Disability is Not Measles. L'instiut Roeher: North York, Ontario 1994, pp 127-151.

62 Holmes CA. Health care and the quality of life: a review. J Adv Nurs 1989; 14: 833-839.

63 Jamieson J, Schmidt T, Britton B. Adults with a Mental Handicap: Their Quality of Life. Province of British Columbia: Ministry of Social Services, Victoria 1993.

64 Meeberg GA. Quality of life: a concept analysis. $J A d v$ Nurs 1993; 18: 32-38.

65 Holman HR. Qualitative inquiry in medical research. $J$ Clin Epidemiol 1993; 46: 29-36.

66 Seers K. Qualitative research. In: Dawes M et al (eds). Evidence-based practice. A primer for health care professionals. Churchill Livingstone: Edinburgh 1999, pp $111-126$

67 Creswell J. Qualitative inquiry and research design: choosing among five traditions. Sage: Thousand Oaks, CA 1998.

68 Hammell KW. The rehabilitation process. In: Stokes M (ed). Physical Management in Neurological Rehabilitation, 2nd ed. Churchill Livingstone: Edinburgh 2004.

69 Good BJ. Medicine, Rationality and Experience. University of Cambridge Press: Cambridge 1994.

70 Menter R. Introduction to high quadriplegia care. In: Whiteneck GG et al (eds). The Management of High Quadriplegia. Demos Publications: New York 1989, pp 1-3.

71 Christiansen C. Defining lives: occupation as identity: an essay on competence, coherence, and the creation of meaning, 1999 Eleanor Clarke Slagle lecture. Am J Occup Ther 1999; 53: 547-558.

72 Jary D, Jary J. The Harper Collins Dictionary of Sociology. Harper Collins: New York 1991.

73 Somers MR, Gibson GD. Reclaiming the epistemological 'other': narrative and the social construction of identity. In: Calhoun C (ed). Social Theory and the Politics of Identity. Blackwells: Oxford 1994, pp 37-99.

74 Wolf DL. Situating feminist dilemmas in fieldwork. In: Wolf DL (ed). Feminist Dilemmas in Fieldwork. Westview Press: Boulder, CO 1996, pp 1-55.

75 Evans RL, Hendricks RD, Connis RT, Haselkorn JK, Ries KR, Mennet TE. Quality of life after spinal cord injury: a literature critique and meta-analysis (19831992). J Am Paraplegia Soc 1994; 17: 60-66.
76 Lin K-H, Chuang C-C, Kao M-J, Tsauo J-Y. Quality of life of spinal cord injured patients in Taiwan: a subgroup study. Spinal Cord 1997; 35: 841-849.

77 Cushman LA, Hassett J. Spinal cord injury: 10 and 15 years after. Paraplegia 1992; 30: 690-696.

78 Fuhrer MJ. The subjective well-being of people with spinal cord injury: relationships to impairment, disability and handicap. Top Spinal Cord Injury Rehabil 1996; 1: 56-71.

79 Gerhart KA. Spinal cord injury outcomes in a population based sample. J Trauma 1991; 31: 1529-1535.

80 Glass CA. The impact of home based ventilator dependence on family life. Paraplegia 1993; 31: 93-101.

81 Post M, de Witte L, van Asbek F, van Dijk A, Schrijvers A. Predictors of health status and life satisfaction in spinal cord injury. Arch Phys Med Rehabil 1998; 78: 395-402.

82 Westgren N, Levi R. Quality of life and traumatic spinal cord injury. Arch Phys Med Rehabil 1998; 79: 1433-1439.

83 Dijkers M. Correlates of quality of life in a spinal cord injured sample. SCI Psychosoc Process 1999; 12: 30-31.

84 Siösteen A, Lundqvist C, Blomstrand C, Sullivan L, Sullivan M. The quality of life of three functional spinal cord injury subgroups in a Swedish community. Paraplegia 1990; 28: 476-488.

85 Vogel LC, Klaas SJ, Lubicky JP, Anderson CJ. Longterm outcomes and life satisfaction of adults who had pediatric spinal cord injuries. Arch Phys Med Rehabil 1998; 79: 1496-1503.

86 Warren L, Wrigley JM, Yoels WG, Fine PR. Factors associated with life satisfaction among a sample of persons with neurotrauma. J Rehabil Res Dev 1996; 33: 404-408.

87 Putzke JD, Richards JS, Hicken BL, DeVivo MJ. Predictors of life satisfaction: A spinal cord injury cohort study. Arch Phys Med Rehabil 2002; 83: 555-561.

88 Franceschini M, Di Clemente B, Rampello A, Nora M, Spizzichino L. Longitudinal outcome 6 years after spinal cord injury. Spinal Cord 2003; 41: 280-285.

89 Richards JS, Osuna FJ, Jaworski TM, Novack TA, Leli DA, Boll TJ. The effectiveness of different methods of defining traumatic brain injury in predicting post-discharge adjustment in a spinal cord injury population. Arch Phys Med Rehabil 1991; 72: 275-279.

90 Krause JS, Dawis RV. Prediction of life satisfaction after spinal cord injury: a four-year longitudinal approach. Rehabil Psychol 1992; 37: 49-60.

91 Whiteneck GG et al. Mortality, morbidity and psychosocial outcomes of persons spinal cord injured more than 20 years ago. Paraplegia 1992; 30: 617-630.

92 Whiteneck GG. Changing attitudes toward life. In: Whiteneck GG (ed). Aging with Spinal Cord Injury. Demos: New York 1993, pp 211-218.

93 McColl MA, Rosenthal C. A model of resource needs of aging spinal cord injured men. Paraplegia 1994; 32: 261-270.

94 Abela MB, Dijkers M. Predicting life satisfaction among spinal cord injured patients one to three years post injury. J Am Paraplegia Soc 1994; 17: 118.

95 Nosek M, Fuhrer MJ, Potter C. Life satisfaction of people with physical disabilities: relationship to personal assistance, disability status and handicap. Rehabil Psychol 1995; 40: 191-202.

96 Kennedy P, Lowe R, Grey N, Short E. Traumatic spinal cord injury and psychological impact: a cross-sectional 
analysis of coping strategies. Br J Clin Psychol 1995; 34: 627-639.

97 Vogel LC, Anderson CJ, Klaas SJ. Life satisfaction and long-term outcomes of paediatric spinal cord injuries. J Spinal Cord Med 1997; 20: 467.

98 Anderson CJ, Vogel LC, Klaas SJ, Lubicky JP. Long term psychosocial outcomes and life satisfaction of patients

with pediatric spinal cord injuries. J Spinal Cord Med 1997; 20: 155.

99 Gagnon L, Noreau L, Laramée M-T. Quality of life in individuals with spinal cord injury. J Spinal Cord Med 1997; 20: 168.

100 Dijkers M. Quality of lief after spinal cord injury: a meta analysis of the effects of disablement components. Spinal Cord 1997; 35: 829-840.

101 Gerhart KA, Weitzenkamp DA, Kennedy P, Glass CA, Charlifue SW. Correlates of stress in long-term spinal cord injury. Spinal Cord 1999; 37: 183-190.

102 Kemp BJ, Krause JS. Depression and life satisfaction among people ageing with post-polio and spinal cord injury. Disabil Rehabil 1999; 21: 241-249.

103 Noreau L, Vachon J. Quality of life in individuals with spinal cord injury: association with specific elements related to health status and social participation. $J$ Spinal Cord Med 2000; 23(Suppl): 58-59.

104 Putzke JD, Richards JS, DeVivo MJ. Quality of life after spinal cord injury caused by gunshot. Arch Phys Med Rehabil 2001; 82: 949-954.

105 Dallmeijer AJ, van der Woude LHV. Health related functional status in men with spinal cord injury: relationship with lesion and endurance capacity. Spinal Cord 2001; 39: 577-583.

106 Anderson CJ, Vogel LC. Domain-specific satisfaction in adults with pediatric-onset spinal cord injuries. Spinal Cord 2003; 41: 684-691.

107 Hallin P, Sullivan M, Kreuter M. Spinal cord injury and quality of life measures: a review of instrument psychometric quality. Spinal Cord 2000; 38: 509-523.

108 Ville I, Ravaud J-F. Tetrafigap Group Subjective wellbeing and severe motor impairments: the Tetrafigap survey on the long-term outcome of tetraplegic spinal cord injured persons. Soc Sci Med 2001; 52: 369-384.

109 Decker SD, Schulz R. Correlates of life satisfaction and depression in middle aged and elderly spinal cord injured persons. Am J Occup Ther 1985; 39: 740-745.

110 Schulz R, Decker S. Long term adjustment to physical disability - the role of social support, perceived control and self-blame. J Person Soc Psychol 1985; 48: $1162-1172$.

111 Pierce CA, Richards JS, Gordon W, Tate D. Life satisfaction following spinal cord injury and the WHO model of Functioning and Disability. SCI Psychosoc Process 1999; 12, 121, 124-127.

112 Clayton KS. Determinants of quality of life in individuals with spinal cord injury. Doctoral Dissertation, University of South Carolina 1992.

113 Krause JS, Crewe NM. Prediction of long term survival of persons with spinal cord injury: an 11-year prospective study. Rehabil Psychol 1987; 32: 205-213.

114 Krause JS. Survival following spinal cord injury: a fifteenyear prospective study. Rehabil Psychol 1991; 36: 89-98.

115 Lundqvist C, Siösteen A, Blomstrand C, Lind B, Sullivan M. Spinal cord injuries: clinical, functional and emotional status. Spine 1991; 16: 78-83.
116 Kemp B, Ettelson D. Quality of life while living and aging with a spinal cord injury and other impairments. Top Spinal Cord Injury Rehabil 2001; 6: 116-127.

117 Deconinck $H$. The health condition of spinal cord injuries in two Afghan towns. Spinal Cord 2003; 41: 303-309.

118 Krause JS. Life satisfaction after spinal cord injury: a descriptive study. Rehabil Psychol 1992; 37: 61-70.

119 McNeil CK, Karunas R, Tate DG. Correlations of quality-of-life after spinal cord injury. J Spinal Cord Med 1998; 21: 61-62.

120 Tate DG, Forchheimer M. Enhancing community reintegration after inpatient rehabilitation for persons with spinal cord injury. Top Spinal Cord Injury Rehabil 1998; 4: 42-55.

121 McColl MA, Stirling P, Walker J, Corey P, Wilkins R. Expectations of independence and life satisfaction among ageing spinal cord injured adults. Disabil Rehabil 1999; 21: 231-240.

122 Bénony H. Daloz L, Bungener C, Chahraoui K, Frenay C, Auvin J. Emotional factors and subjective quality of life in subjects with spinal cord injuries. Am J Phys Med Rehabil 2002; 81: 437-445.

123 Hansen NS, Forchheimer M, Tate DG, Luera G. Relationships among community reintegration, coping strategies, and life satisfaction in a sample of persons with spinal cord injury. Top Spinal Cord Injury Rehabil 1998; 4: $56-72$.

124 Krause JS, Kjorsvig JM. Mortality after spinal cord injury: a four year prospective study. Arch Phys Med Rehabil 1992; 73: 558-563.

125 Pentland W, Harvey AS, Walker J. The relationship between time use and health and well-being in men with spinal cord injury. J Occup Sci 1998; 5: 14-25.

126 Thibodaux LR. Habitus and health lifestyle two years after spinal cord injury. Occup Ther J Res 2002; 22(Suppl): 85S.

127 Krause JS. Adjustment after spinal cord injury: a 9 year longitudinal study. Arch Phys Med Rehabil 1997; 78: 651-657.

128 Stensman R. Adjustment to traumatic spinal cord injury: a longitudinal study of self-reported quality of life. Paraplegia 1994; 32: 416-422.

129 Anke AGW, Stenehjem AE, Stanghelle JK. Pain and life quality within 2 years of spinal cord injury. Paraplegia 1995; 33: 555-559.

130 Whiteneck GG. Measuring what matters: key rehabilitation outcomes. Arch Phys Med Rehabil 1994; 75: 1073-1976.

131 Johnston MV, Granger CV. Outcomes research in medical rehabilitation. Am J Phys Med Rehabil 1994; 73: $296-303$.

132 Fuhrer MJ. Subjective well-being: implications for medical rehabilitation outcomes and models of disablement. Am J Phys Med Rehabil 1994; 73: 358-364.

133 Batterham RW, Dunt DR, Disler PB. Can we achieve accountability for long-term outcomes? Arch Phys Med Rehabil 1996; 77: 1219-1225.

134 Whiteneck GG. Evaluating outcome after spinal cord injury: what determines success? J Spinal Cord Med 1997; 20: $179-185$.

135 Widerström-Noga EG, Felipe-Cuervo E, Broton JG, Duncan RC, Yezierski RP. Perceived difficulty in dealing with consequences of spinal cord injury. Arch Phys Med Rehabil 1999; 80: 580-586. 
136 Ozer M. Rehabilitation outcomes and patient participation. WFNR Update: The World Forum for Neurological Rehabilitation 2000, December 3.

137 Bach CA, McDaniel RW. Quality of life in quadriplegic adults: a focus group study. Rehabil Nurs 1993; 18: 364-367,374.

138 Flanagan JC. Measurement of quality of life: current state of the art. Arch Phys Med Rehabil 1982; 63: 56-59.

139 Boswell BB. Exploring quality of life of adults with spinal cord injuries. Percept Motor Skills 1997; 84: 1149-1150.

140 Duggan $\mathrm{CH}$, Dijkers M. Quality of life - peaks and valleys: a qualitative analysis of the narratives of persons with spinal cord injuries. Can J Rehabil 1999; 12: 181-191.

141 Duggan CH, Dijkers M. Quality of life after spinal cord injury: a qualitative study. Rehabil Psychol 2001; 46: 3-27.

142 Duggan $\mathrm{CH}$, Dijkers $\mathrm{M}$. Etiology, disablement, and quality of life: interpersonal violence versus other causes of spinal cord injury. Top Spinal Cord Injury Rehabil 1999; 4: 65-85.

143 Duggan CH, Lysack C, Dijkers M, Jeji T. Daily life in a nursing home: Impact on quality of life after a spinal cord injury. Top Spinal Cord Injury Rehabil 2002; 7: 112-131.

144 Duggan C, Lysack C. How individuals interpret changes in quality of life following traumatic spinal cord injury. J Spinal Cord Med 2001; 24(Suppl 1): S34.

145 Crewe NM. Gains and losses due to spinal cord injury: views across 20 years. Top Spinal Cord Injury Rehabil 1996; 2: 46-57.

146 Gill CJ. Divided understandings. The social experience of disability. In: Albrecht GL, Seelman KD, Bury M (eds). Handbook of Disability Studies. Sage: London 2001, pp 351-372.

147 Carpenter C. The experience of spinal cord injury: the individual's perspective - implications for rehabilitation practice. Phys Therapy 1994; 74: 614-629.

148 Burnham L, Werner G. The high-level tetraplegic: psychological survival and adjustment. Paraplegia 197879; 16: 184-192.

149 Whiteneck GG et al. A collaborative study of high quadriplegia. Englewood, CO: Craig Hospital 1985.

150 Fuhrer MJ, Carter RE, Donovan WH, Rossi CD, Wilkerson MA. Post-discharge outcomes for ventilator dependent quadriplegics. Arch Phys Med Rehabil 1987; 68: $353-356$.

151 Maynard FM, Muth AS. The choice to end life as a ventilator-dependent quadriplegic. Arch Phys Med Rehabil 1987; 68: 862-864.

152 Globe and Mail. Woman makes plea to end life. Globe and Mail, 29 November, 1991, Section A:4.

153 Kinney WB, Coyle CP. Predicting life satisfaction among adults with physical disabilities. Arch Phys Med Rehabil 1992; 73: 863-869.

154 Morgan DL. Practical strategies for combining qualitative and quantitative methods: applications to health research. Qual Health Res 1998; 8: 362-376.

155 Hammell KW, Carpenter C. Introduction to qualitative research in occupational therapy and physical therapy. In:
Hammell KW, Carpenter C, Dyck I (eds). Using Qualitative Research. A Practical Introduction for Occupational and Physical Therapists. Churchill Livingstone: Edinburgh 2000, pp 1-12.

156 Miller WL, Crabtree BF. Clinical research. In: Denzin N, Lincoln Y (eds). Handbook of Qualitative Research, 2nd edn. Sage: London 2000, pp 607-631.

157 Black N. Why we need qualitative research. J Epidemiol Community Health 1994; 48: 425-426.

158 Pope C, Mays N. Reaching the parts other methods cannot reach: an introduction to qualitative methods in health and health services research. BMJ 1995; 311: $42-45$.

159 Laliberte-Rudman D, Yu B, Scott E, Pajouhandeh P. Exploration of the perspectives of persons with schizophrenia regarding quality of life. Am J Occup Ther 2000; 54: 137-147.

160 Mallinson S. Listening to respondents: a qualitative assessment of the Short-Form 36 Health Status Questionnaire. Soc Sci Med 2002; 54: 11-21.

161 McLaughlin E. Oppositional poverty: the quantitative/ qualitative divide and other dichotomies. Sociol Rev 1991; 39: 292-308.

162 Hammell KW, Carpenter C. Qualitative Research in Evidence-based Rehabilitation. Churchill Livingstone: Edinburgh 2004.

163 Dixon-Woods M, Fitzpatrick R. Qualitative research in systematic reviews. BMJ 2001; 323: 765-766.

164 Beck C. Mothering multiples: a meta-synthesis of qualitative research. Am J Matern Child Nurs 2002; 27: 214-221.

165 Campbell $\mathrm{R}$ et al. Evaluating meta-ethnography: a synthesis of qualitative research on lay experiences of diabetes and diabetes care. Soc Sci Med 2003; 56: 671-684.

166 Higginson IJ et al. Do hospital-based palliative teams improve care for patients or families at the end of life? J Pain Symptom Manage 2002; 23: 96-106.

167 Safilios-Rothschild C. Disabled persons' self-definitions and their implications for rehabilitation. In: Brechin A, Liddiard P, Swain J (eds). Handicap in a Social World. Open University and Hodder \& Stoughton: London 1981, pp 5-13.

168 Linton S. Claiming Disability: Knowledge and Identity. New York University Press: New York 1998.

169 Rockhill K. And still I fight. In: Tremain S (ed). Pushing the Limits. Disabled Dykes Produce Culture. Women's Press: Toronto 1996, pp 172-187.

170 Jongbloed L, Crichton A. A new definition of disability: implications for rehabilitation practice and social policy. Can J Occup Ther 1990; 57: 32-38.

171 Chase B, Cornille T, English R. Life satisfaction among persons with spinal cord injuries. J Rehabil 2000; 66: $14-20$.

172 Law M. The environment: a focus for occupational therapy. Can J Occup Ther 1991; 58: 171-180.

173 Hammell KW. Spinal Cord Injury Rehabilitation. Chapman \& Hall: London 1995. 